\title{
Una relación de lo razonable y la teoría de la argumentación con el derecho*
}

\section{A relationship of the reasonable and theory of argumentation to law}

\author{
Diego Andrés López Castaño**, Gloria Mercedes Castaño Garay ${ }^{\star * *}$
}

\begin{abstract}
* Los autores agradecen a la Universidad Tecnológica de Pereira, en particular a la Maestría en Filosofía, por el apoyo para la realización de actividades académicas investigativas.

** Profesional en filosofía. Docente Universidad La Gran Colombia Seccional Armenia. Docente Universidad del Quindio. Maestrante de Filosofia, Universidad Tecnológica de Pereira.lopezcasdiego@miugca.edu.co

*** Abogada. Especialista en derecho probatorio penal. Maestrante de Filosofia, Universidad Tecnológica de Pereira. Fiscalía General de la Nación.glomercitas@gmail.com
\end{abstract}

Cómo citar: López, D.A., Castaño, G.M. (2016). Una relación de lo razonable y la teoría de la argumentación con el derecho. Inciso, 18 (2):105-116

Recibido: 12/09/2016| Revisado: 20/09/2016| Aceptado: 08/11/16

\section{Resumen}

Este artículo pretende evaluar la idea de que la teoría de la argumentación es una disciplina inscrita en el ámbito de lo razonable. Para lograr este cometido se hace, de la mano de Chaïm Perelman, una presentación general de la teoría de la argumentación, conocida también como nueva retórica. Luego, se muestran las relaciones y diferencias entre lo racional y lo razonable. Se afirma, así mismo, que lo razonable, en tanto ejercicio de la razón, es aquello coherente con el sentido común, entendiendo este último a la manera de Karl R. Popper. Y finalmente se muestra un ejemplo de cómo el derecho, si bien intenta construir una herramienta racional como el silogismo jurídico, se mantiene, en muchas ocasiones, dentro del ámbito de lo razonable.

Palabras clave: Racional, razonable, sentido común, teoría de la argumentación.

\begin{abstract}
This article evaluates the idea that theory of argumentation is a discipline within the scope of the reasonable. In order to achieve this purpose, a general presentation of the theory of argumentation, also known as the new rhetoric, is performed supported by Chaïm Perelman. Then, a relationship and difference between the rational and the reasonable is shown. It is likewise claimed, that the reasonable, as the exercise of the reason, is, what is coherent to common sense, the latter understood as done by Karl R. Popper. And finally, an example is shown on how the law, notwithstanding intending to build a rational tool, such as the legal syllogism, is maintained, many times, within the scope of the reasonable.
\end{abstract}

Keywords: rational, reasonable, common sense, theory of argumentation. 


\section{Introducción}

El subjetivismo absoluto de la posmodernidad ha calado hondamente. De hecho, se vuelve fácil para el individuo cuando no tiene que sustentar las decisiones que toma o las opiniones que presenta, pues todo se resuelve apelando a la relatividad absoluta y a una pretendida inexistencia de criterio objetivo ${ }^{1}$ para las valoraciones morales, estéticas, políticas, etc. El resultado es un estado de incomunicación que genera conflictos que no se resuelven, o cuya resolución queda en manos de la violencia. De otra parte tenemos los totalitarismos del siglo XX que, apelando a una inobjetable objetividad, pasaron por encima de las diferentes formas de asumir la existencia. Las diferencias de pensamiento se asumían como errores a corregir y los mecanismos pedagógicos utilizados pasaban muchas veces por la supresión del otro. Ni una posición ni otra resultan satisfactorias para la construcción de la vida comunitaria en una sociedad occidental que apela constantemente a la democracia y a la dignidad humana. De tal manera que se necesita una forma de alcanzar acuerdos razonables que superen las imposiciones arbitrarias de la subjetividad.

Lastimosamente la retórica, tan útil para enfrentar situaciones como las mencionadas, ha sido objeto de menosprecio histórico. Cotidianamente se utilizan las palabras sofista o retórico para apelar al embustero, al que engaña, al que renuncia a la razón y usa las palabras para seducir las pasiones. Esta actitud se establece particularmente desde la modernidad cuando Descartes desprecia como falso todo aquello que no pueda probarse con distinción y claridad. En esta misma línea se encuentran los positivistas lógicos, quienes quisieron convencer al mundo de que sólo tenía sentido aquello ajustado a las leyes de la lógica; lo racional, lo evidente, lo que se pudiera probar. Todo lo demás quedaba fuera del dominio de la razón, lo afectivo, lo valorativo, lo volitivo, es decir, aquello a lo que la retórica se enfrenta diariamente.

En La eliminación de la metafísica (1984), Alfred Ayer plantea que para probar la existencia 1. Se entiende la objetividad como contraria a la subjetividad. En este caso la verdad depende del objeto en cuestión y no del sujeto observador. Un criterio objetivo de los juicios morales implica entonces que la verdad moral depende del hecho mismo evaluado y no del deseo del evaluador. Esto supondría la posibilidad de acuerdos razonables sobre lo mejor en términos morales. de sentido en una declaración es necesario acudir al criterio de verificabilidad, consistente en el conocimiento de las condiciones empíricas conducentes a aceptar su verdad. No obstante, el criterio de verificabilidad funciona al predicar sobre objetos de naturaleza material, pero al hablar de realidades morales no aplica. Según Ayer serían entonces pseudo proposiciones sin sentido, o más bien contrasentidos. Se trataría simplemente de frases emocionalmente significantes para quien las pronuncie, pero sin posibilidad de objetividad. Hablando de la expulsión de los metafísicos de la filosofía y ponerlos como poetas desplazados dice:

\section{Como sus declaraciones no tienen significación literal alguna, no son objeto de ningún criterio de verdad o falsedad, pero pueden, sin embargo, servir para expresar o despertar emoción, y, en consecuencia, ser objeto de normas éticas o estéticas. Y se sugiere que pueden tener un valor considerable, como medios de inspiración moral, o incluso como obras de arte (Ayer,1984:49)}

Sin embargo, a renglón seguido, dice que ni siquiera pueden contarse entre los poetas, porque estos últimos, al menos, buscan alguna significación literal en sus obras. Pero esta significación no es algo de lo que pueda predicarse verdad o falsedad, porque está dentro de lo emotivo.

Si esto es así, hablar de la política, la ética, el arte, es algo alejado de lo racional y en principio tiende a quedar abandonado a lo irracional, a lo meramente emotivo. Ante semejante pretensión, el llamado de Enrique Dussel (1982) a Wittgenstein tiene una amplia validez:

Si lo ético cae entre lo que "de lo que no se puede hablar, mejor es callar", es necesario que el campesino salvadoreño calle del napalm que se le arroja para impedir su liberación. Es posible que la aristocracia vienesa - a la que pertenecía el gran lógico- pueda ser escéptica y hablar de pocas cosas. Pero ese escepticismo se vuelve éticamente cínico cuando es necesario gritar — no sólo hablar - al sistema sobre su horrible perversidad, y formular positivamente lo necesario para la liberación (Dussel,1982:599)

Es difícil, cuando no imposible, aceptar que asuntos relevantes para la vida humana queden al arbitrio del capricho subjetivo, pues fácilmente puede ser 
el capricho subjetivo del opresor. Algo se tiene que poder decir contra la injusticia y no será precisamente una demostración lógica o matemática que lo haga.

El mundo actual, y en particular la sociedad colombiana, se enfrenta a situaciones conflictivas que resultan de diferencias en las valoraciones, por parte de grupos o individuos, sobre temas de particular relevancia para la vida en común. La incapacidad para comprender los puntos de vista ajenos y hacer comprender los propios culmina, en no pocas oportunidades, en actos de violencia que tienden a perpetuarse. Un mejor conocimiento de la teoría de la argumentación podría ayudar a enfrentar adecuadamente las diferencias y por ende a prevenir o solucionar los conflictos.

Una forma de enfrentar situaciones de este tipo se encuentra en el uso del sistema judicial. Apelar al derecho como elemento de resolución de conflictos es la esperanza de muchos ciudadanos que prefieren alejarse de la violencia y acercarse al diálogo. Este artículo, además de mostrar cómo la teoría de la argumentación se inscribe en el ámbito de lo razonable, también muestra cómo la discusión jurídica queda inscrita en el campo de lo argumentativo, más allá de lo meramente racional.

\section{Una exposición de la teoría de la argumentación}

La primera definición de teoría de la argumentación que enuncia Chaïm Perelman (1989) la presenta como el estudio de las técnicas de persuasión, en donde participan orador y auditorio, y se entiende principalmente desde la argumentación escrita. Recuerda que el auditorio (público) no debe confundirse con la simple masa reunida, sino que éste es más bien una comunidad de interés. Y nos advierte que dicho estudio trabaja con lenguajes utilizados comúnmente en la comunicación y no con lenguajes formales.

Entender la importancia del auditorio para la teoría de la argumentación es fundamental, porque implica que los argumentos, para lograr adhesión, no dependen únicamente de los criterios o creencias del orador, sino que tienen que tomar en cuenta los preconceptos y creencias de aquel. De tal manera que los argumentos no son de aplicación absoluta sino relativa; para cada auditorio debe pensarse un argumento particular.
El profesor Adolfo León Gómez Giraldo nos recuerda que el surgimiento de la nueva teoría de la argumentación fue consecuencia del nacimiento de la lógica formal contemporánea, "que trataba de explicitar los procedimientos mediante los cuales razonaban de manera efectiva los matemáticos" (Gómez,2001:25-26). Así mismo, afirma que es una disciplina descriptiva que indirectamente puede convertirse en normativa por acción del individuo estudioso. Lo que recuerda la lógica aristotélica (con la que tiene gran afinidad) que considera, según indica el profesor Gregorio Posada (2011), que su estudio es "una preparación acerca de la manera como los conceptos y las proposiciones se enlazan para hacer descripciones de la realidad" (p. 50-51). De la misma manera, la nueva retórica no prescribe cómo argumentar bien, sino que describe cómo, en el lenguaje cotidiano, se intenta persuadir al auditorio. No se piensa entonces la teoría de la argumentación como una disciplina opuesta a la lógica, sino precisamente deudora de esta en tanto generadora de la preocupación por la razonabilidad de lo valorativo.

Perelman afirma que la nueva retórica es un regreso a los estudios clásicos sobre el arte de persuadir y convencer ante el olvido de estos por parte de los filósofos modernos. En ese sentido, Gómez muestra que el nacimiento de la argumentación puede rastrearse hasta la retórica de la antigüedad teorizada por los sofistas, y atribuye su primer uso a Corax al hacer la teoría del doble discurso ${ }^{2}$. Los sofistas, como se sabe, eran maestros de retórica que tenían como intención educar ciudadanos demócratas. Pero estos hombres fueron maltratados por la aristocracia, que hacía oposición entre sofistas (hombres de acción) y filósofos (hombres contemplativos), acusando a los primeros de ser una especie de prostitutos que vendían su saber por dinero. Así, se presenta la tesis del poema de Parménides como punto de partida para un ejercicio de doble discurso de Gorgias. Al plantear unas tesis contrarias a las de Parménides de Elea, Gorgias cree tener una prueba del discurso que podría ponerse al servicio de lo irracional y no

\footnotetext{
2. No hace referencia a los Dissoi logoi, texto atribuido a Protágoras de Abdera, sino a la actividad argumentativa que el mismo Aristóteles atribuye al Arte de Corax en su Retórica (1994), consistente en afirmar la improbabilidad de cometer un acto del que se ha sido acusado: “(...) si está expuesto a una acusación, por ejemplo porque es fuerte, podría hacerlo arguyendo que no es probable que haya hecho algo que a todo el mundo le parecería probable que hubiera hecho él". (Aristóteles, 1994:231)
} 
de la persuasión. ${ }^{3}$ Sin embargo no todos los sofistas aceptaban este uso de la argumentación. Protágoras, por ejemplo, se presenta como un agnóstico que plantea la importancia de la argumentación para hablar de asuntos prácticos como las necesidades de la vida en la polis, más que para hablar de temas divinos. Con esto se afirma la existencia de sofistas honestos y deshonestos y se muestra el sentido inicial del sofista como sabio, no como maestro del engaño, aunque para algunos pensadores modernos y contemporáneos su arte, la retórica y la dialéctica, esté desprestigiado.

Una razón para tal desprestigio puede encontrarse, como nos dice el profesor Jairo Urrea Henao (2010), en la discusión entre retóricos y filósofos:

Los unos consideran que mediante el diálogo se llega a la verdad y los otros que mediante los argumentos se llega a un acuerdo. Porque para los dialécticos existían las verdades y los principios, mientras que para los retóricos estos no existían, sino las opiniones y lo verosímil (Urrea,2010:30)

Los filósofos no aceptaban las opiniones y lo verosímil, propios del discurso de los sofistas, como elementos que condujeran a la verdad. De tal manera que consideraban a estos maestros de retórica como simples maestros del engaño. Esta idea será también retomada por Descartes (1999a), quien no acepta como principio del edificio del conocimiento nada amparado en la opinión o lo probable, sino sólo aquello claro y distinto; la verdad debe ser evidente y no ofrecer ningún atisbo de duda.

No obstante Werner Jaeger (2001) nos recuerda que la tarea encomendada a los sofistas es muy diferente a la de engañar o enseñar a engañar:

Así el estado del siglo $\mathrm{V}$ es el punto de partida histórico necesario del gran movimiento educador que da el sello a este siglo y al siguiente y en el cual tiene su origen la idea occidental de la cultura. Como lo vieron los griegos, es íntegramente político-pedagógica. La idea de la educación nació de las necesidades más profundas de la vida del estado y consistía en la conveniencia de utilizar la fuerza formadora del saber, la nueva

3. Las tesis del poema de Parménides son: El ser es, el ser es pensable y el ser es expresable. Gorgias contrapone las siguientes: El ser no es, si el ser fuese no sería pensable y si fuese pensable no sería expresable en palabras. fuerza espiritual del tiempo, y ponerla al servicio de aquella tarea (Jaeger,2001: 264).

El ciudadano libre, descendiente de la estirpe de ática, debe convertirse en un miembro consciente de la sociedad y ponerse al servicio de la comunidad. El educador tiene la intención de formar a los ciudadanos en la areté e igualarlos ya no por una condición aristocrática de sangre, sino por la formación del espíritu, esto es: por la razón. Si bien las discusiones del ágora eran acuerdos sobre lo mejor para la polis, dichos acuerdos estaban amparados siempre en la mejor razón, aunque esta no fuera necesariamente evidente.

Gómez presenta la teoría de la argumentación como nueva disciplina nacida de la mano de Perelman y Lucie Olbrechts-Tyteca. Su aparición está determinada por la crisis tanto en las ciencias naturales como en las ciencias formales del siglo $\mathrm{XX}$, que produjo un desarrollo de la lógica, las matemáticas y una ideología cientificista. En medio de estas situaciones aparece el Círculo de Viena, organización que planteaba como papel de la filosofía, la distinción entre lo que es ciencia y lo que no. Para ello pretendían crear un lenguaje común a todas las ciencias. Dicho grupo consideraba los enunciados científicos como los únicos cargados de sentido. Es decir, las reflexiones que ordenan las decisiones de la vida cotidiana son un sinsentido. Es en este clima, y a manos de los lógicos polacos, donde se forma Perelman. Allí surge su antinomia vital: aceptar sin más la racionalidad positivista o ampliar este concepto para abarcar las reflexiones sobre la vida.

Afrontando su antinomia vital, Perelman se pone en la búsqueda de una lógica de los valores y hace el descubrimiento de una vieja disciplina que justifica cualquier clase de tesis. El filósofo se encuentra con Aristóteles como primer desarrollador de los métodos analítico y demostrativo. Y se da cuenta que en Tópicos y Refutaciones se estudia la lógica de la opinión. De manera pues que la Retórica junto con Tópicos y Refutaciones aparecen como primer tratado de argumentación. A partir de ese descubrimiento empezará la construcción de la nueva retórica. En sus propias palabras:

La nueva retórica consiste, por tanto, en una teoría de la argumentación, complementaria de la teoría 
de la demostración objeto de la lógica formal. Mientras la ciencia se basa en la razón teorética, con sus categorías de verdad y evidencia y su método demostrativo, la retórica, la dialéctica y la filosofía se basan en la razón práctica, con sus categorías de lo verosímil y la decisión razonable y su método argumentativo, justificativo. La razón teorética se supedita a la razón práctica, porque la noción de justicia, alumbrada por ésta, es la base del principio de contradicción, supuesto fundamental de aquella (Perelman,1989:17)

No se trata pues de un ejercicio opuesto a la lógica y a la racionalidad científica de la modernidad. No es una negación de la manera de entender la naturaleza material alcanzada por la ciencia poscartesiana. La teoría de la argumentación pretende más bien ampliar el horizonte de la razón humana, aparece como una posibilidad de comprender mejor el mundo al aplicarse a aquello que escapa a la evidencia, sin que por eso caiga en la irracionalidad.

Perelman afirma que, para lograr ese cometido, la argumentación recurre a la persuasión y a la convicción. Sobre estas, Gómez plantea que la persuasión normalmente se asume como irracional y la convicción usualmente se presume racional. Así mismo, recuerda que Kant también hace diferenciación entre estas dos, pero plantea que la persuasión es subjetiva y la convicción objetiva. Gómez cree que filósofos como Kant, Pascal y Descartes, que afirmaban esta posición, buscaban una filosofía basada en verdades irrefutables, frente a otros filósofos que creen en la posibilidad de la existencia de buenas opiniones basadas en la razón. Entre estos últimos está J. N. Garver, quien hace un análisis del verbo persuadir. Plantea que no es un verbo de estado, sino un verbo de logro. Así mismo plantea que es un verbo defectivo, conjugable normalmente en pasado. La persuasión aparece entonces como relación entre orador, auditorio y discurso, con dos elementos: "uno teórico (como disposición a la acción) y otro práctico (como movimiento directo hacia la acción)" (Gómez, 2001:43) Se plantean así dos usos del verbo persuadir: Uno razonable legítimo, otro irracional ilegítimo.

Esta distinción puede seguirse inclusive en la persuasión vista desde la Retórica de Aristóteles (1994) cuyos tres pilares son $\lambda o ́ \gamma o \varsigma, \pi \alpha ́ \theta 0 \varsigma$ y $\tilde{\eta} \theta$ os, los últimos deberían estar supeditados al primero

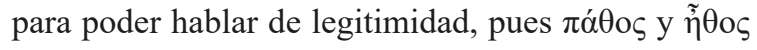

atienden a elementos físicos y morales del orador, mientras que $\lambda o ́ \gamma o \varsigma$ es la apelación directa a la razón. De tal manera que si el $\lambda o ́ \gamma o \varsigma$ se utiliza como apoyo a los otros dos la persuasión sería ilegítima.

Así pues, esta aventura en la que se ha embarcado Perelman le obliga a diferenciar la manera en que es usada la razón desde Descartes y que es retomada por los positivistas lógicos, de la manera en que es usada la razón en la argumentación desde los sofistas en la Grecia clásica y retomada en la nueva retórica; de esta manera podrá mostrar que el ejercicio argumentativo no es algo irracional. El apartado siguiente de este trabajo hace esa diferenciación entre lo racional y lo razonable.

\section{Lo racional y lo razonable}

El texto de Perelman The Rational and the Reasonable (1979), fue expuesto en el coloquio de Rationality Today en Otawa en 1977. Allí se plantea la no equivalencia entre los términos racional y razonable. Se presenta lo racional como razón matemática, evidente y que se impone a todo ser de razón. Como se dice en el Tratado:

La lógica de nuestro siglo se ha decantado en exclusiva hacia la lógica formal, demostrativa, arrojando así al terreno de lo ilógico, de lo irracional, todo el contenido de las ciencias humanas y sociales, que, como la ética, se resisten a una formalización sólo posible con verdades universalmente convincentes, demostrables con pruebas constrictivas (Perelman,1989:8-9).

Dicha racionalidad es posible en un dominio teórico, pero catastrófica en el dominio del comportamiento humano, pues implicaría un hombre frío, calculador, ajeno a cualquier afecto o sentimiento.

Este hombre racional es el hombre cartesiano que afirma: "Sean cuales sean los argumentos y pruebas de que me sirva, siempre vendré a esta conclusión: que sólo las cosas que conozco clara y distintamente tienen fuerza para persuadirme por completo" (Descartes,1999b:79) Y lo que se conoce clara y distintamente es lo que se ajusta a la cientificidad, a los criterios de la lógica y la matemática. Lo opinable, lo que ofrezca una duda mínima debe ser desechado como falso. 
Por otra parte, la idea de hombre razonable se presenta como defensa de una razón moral universalizable al estilo del imperativo categórico Kantiano: "obra sólo según la máxima a través de la cual puedas querer al mismo tiempo que se convierta en una ley universal" (Kant,1996:173). Es decir, el sentido común, en tanto aquello aceptado comúnmente por los miembros de una sociedad y por lo tanto universalizable, se convierte en el criterio de la moralidad ${ }^{4}$. Acto seguido, tomando como ejemplo al moralista inglés Henry Sidwick, considera Perelman que la imparcialidad, en tanto posibilidad de intercambiabilidad, puede fungir como criterio de la razón práctica. De tal manera que, no se puede juzgar que determinada acción está justificada para unos, pero no para otros. Sin embargo niega la regla de oro ("has a tu prójimo lo que tú quisieras que tu prójimo te hiciera") como criterio suficiente de moralidad, pues aquello que quiera ser un principio de acción razonable debe poder ser universalizable y no responder simplemente a los intereses particulares de un individuo o grupo.

Así pues, lo racional no es precisamente un buen criterio de lo moralmente preferible, en la medida que ciertas decisiones pueden ser perfectamente racionales, pero difícilmente aceptadas como adecuadas por algún grupo de personas. Entre otras cosas porque, siendo lo racional la razón lógica, es importante tener en cuenta que esta no explica cómo deben pensar las personas sino más bien, describe la manera en que efectivamente lo hacen, como recuerda Von Wright:

Así, pues, la concepción de las leyes de la lógica como prescriptivas de la forma en que la gente debe pensar nos lleva a una concepción de que estas leyes son, primordialmente, descriptivas. Lo que, en esta nueva concepción, las leyes de la lógica describen no es, sin embargo, cómo piensa la gente sino cómo están constituidas las entidades lógicas (Von Wright,1970:24)

Es decir, la lógica sólo llega a convertirse en una disciplina normativa por la acción del estudioso

4. Cabe aclarar que el sentido común kantiano no está ubicado en el orden del lenguaje sino en el orden del sentir. No aparece pues en su filosofía moral, sino en su Crítica del Juicio (1991), por tanto no hace parte del conocimiento sino del sentimiento. En ese sentido puede no ser equiparable con el sentido común al que apela Perelman, y tal vez no es la intención de este. El imperativo categórico puede servir aquí como excusa para plantear que la moralidad no depende exclusivamente del sujeto, sino que puede ser universalizable y en ese sentido objeto de discusión desde la razón. de la misma. Y está claro que exigir a las personas que se vuelvan eruditos en lógica para poder tomar decisiones en la vida es poco menos que absurdo. Sin embargo, esto no quiere decir que no haya razón en las decisiones que no siguen un esquema lógico.

Podríamos, de alguna manera, estar de acuerdo con el profesor Pablo Rolando Arango (2005), quien ante la fuerza que ha tomado lo que llama religión de nuestros días, sostiene que lo moral es objetivo y que no depende de ninguna autoridad. La tesis defendida por el relativismo moral plantea que lo moralmente correcto o incorrecto depende de cada cultura o de cada individuo. En este sentido el relativismo moral estaría indicando que un criterio de lo moralmente preferible puede ser, sin ningún problema, el capricho de un individuo o la costumbre impuesta por las instituciones sociales. De tal manera que allí no habría necesidad de la razón y por lo tanto no se puede hablar de razón ética.

La objetividad moral, por el contrario necesita de la razón: "Así, la objetividad de los juicios morales consiste - si es que la hay-en que un juicio moral puede ser verdadero o falso independientemente de lo que cualquier persona o cultura piense con respecto a ese juicio" (Arango,2005:23) Y lo que garantiza esa independencia es la razón. Ahora, un lector del texto de Arango podrá decir que el uso de la razón al que apela el autor es precisamente el racional y no el razonable, especialmente porque él mismo defiende la objetividad como posibilidad de una discusión racional. A eso podríamos responder que tal vez no utilizamos el término en el mismo sentido y cuando el profesor lo utiliza hace referencia al uso de la razón en general. Y al aceptar que:

Podemos sostener que la verdad de un juicio de valor como "no se debe matar" depende de factores circunstanciales —como, por ejemplo, en los casos de defensa personal, el hecho de que la propia vida puede perderse si no se mata a otro-, y en este sentido los juicios morales son relativos (Arango,2005:21) ${ }^{5}$

5. Esta aporía es resuelta por Arango presentando la relación de oposición entre los conceptos absoluto - relativo y objetivo - subjetivo. De estos cada uno tiene un contrario que no se puede afirmar al mismo tiempo sin caer en contradicción, lo otros dos conceptos se pueden afirmar sin problema al mismo tiempo. Así, no se puede afirmar que algo es al mismo tiempo absoluto y relativo, pero sí se puede afirmar que algo es al mismo tiempo relativo y objetivo. En ese sentido la moralidad del acto de matar es relativa a las circunstancias, pero es objetiva al mismo tiempo. 
Lo que se acepta es que los juicios éticos no son, ni pretenden serlo, exactos, aplicables universalmente de la misma manera, es decir, no son científicos. Por lo tanto, las buenas razones éticas se enmarcan dentro de lo razonable y no dentro de lo racional.

Por otro lado, Perelman se pregunta sobre esta dialéctica (racional, razonable) en el derecho. Y para responder explica que históricamente ha existido una identificación entre lo racional y el derecho natural y se apoya en una cita de Cicerón sobre la eternidad e inmutabilidad de la ley natural, según la cual: "These laws present immutable justice, the same everywhere and always; whether written or unwritten, no human authority can abolish or change them" (Perelman,1979:5)6. Y aunque actualmente, y de manera análoga al papel de Dios, el legislador se asume como racional, contrario a la historia hoy no se acepta la universalidad ni inmutabilidad de las leyes. En el derecho actual lo razonable y lo no razonable son los criterios de lo aceptable o inaceptable:

The ideas of the reasonable and the unreasonable In law play a completely different role: they provide a framework In which any legal authority has to runetlon. What is unreasonable ls always unacceptable In law: the existence of this framework makes it impossible to reduce the legal system to a formal and positivistic concept. (Perelman, 1979:5) ${ }^{7}$

Se supone, actualmente, que el poder otorgado a una institución legal será ejercido razonablemente. De manera tal que se dan diferentes nombres al ejercicio no razonable del poder y en diferentes tipos de derecho existe un principio que prohíbe dicho ejercicio. Tomando un ejemplo del código de Napoleón, Perelman plantea la necesidad de razonabilidad para el derecho, es decir, no ir más allá de la razón y la equidad. Se tiene entonces que lo razonable, aquello contrario a los objetivos globales, es el límite de cualquier poder discrecional. En la posibilidad de elección entre eventualidades, lo no razonable es el límite intransgredible del ejercicio del poder legal so pena de censura.

6. Estas leyes presentan una justicia inmutable, las mismas en cualquier parte y siempre; estén escritas o no, ninguna autoridad humana puede abolirlas o cambiarlas. (Traducción libre)

7. Las ideas de lo razonable y lo no razonable en derecho juegan un rol completamente diferente: ellas proveen un marco en el cual cualquier autoridad legal tiene que funcionar. Lo que no es razonable es siempre inaceptable en derecho: la existencia de este marco hace imposible reducir el sistema legal a un concepto formal y positivista. (Traducción libre)
En el derecho, lo racional es aquello ajustado al sistema de normas, lo razonable es una característica de la decisión en tanto aceptable o no por la opinión pública. Aparece así la necesidad de modificación del sistema racional cuando conduce a conclusiones no razonables.

Perelman cuenta que a veces hay conflictos entre la Suprema Corte y las cortes intermedias de apelación, pues la primera trata de mantenerse fiel al espíritu del sistema y la coherencia lógica de la decisión. Mientras que las segundas consideran las consecuencias sociales de las decisiones. Presenta como ejemplo de decisiones contrarias de las cortes en un mismo caso, el de una mujer belga, abandonada por su esposo italiano, que solicita el divorcio. Ante la no razonabilidad de la decisión tomada en dicho caso, se introdujo un cambio en la legislación. Así mismo muestra un ejemplo de conciliación entre el sistema racional y la razonabilidad de las decisiones a partir de la introducción de un cambio en el primero, para mostrar que el sistema cambia para ajustarse a lo razonable.

Concluye Perelman planteando que lo razonable sirve como criterio ante la ausencia de una legislación aplicable a todos los casos. Es decir, lo razonable sirve como solución provisional mientras se construye una legislación más satisfactoria.

Se podría entonces decir que la razón es una característica propiamente humana, de la cual se puede hacer dos usos: uno racional, otro razonable. El primero, como un sistema cerrado amparado en principios, se refiere a aquello que es demostrable, evidente. Este uso se inscribe en un lenguaje lógico y matemático propio del ejercicio científico. El segundo muestra lo que queda fuera del sistema y lo abre, permitiendo acercarse a aquello de lo que no se puede predicar características absolutas, aunque no por eso caprichosas. Se inscribe dentro de lo argumentativo, de lo retórico y es propio del ejercicio filosófico y del discurso cotidiano del sentido común.

Sin embargo, decir que el sentido común puede fungir como criterio de una argumentación razonable no es algo exento de polémica. Frecuentemente creencias propias del sentido común son desenmascaradas como falsas. Sin embargo, eso no implica necesariamente 
que el sentido común sea irracional, de la misma manera que no creemos que la ciencia sea irracional cuando una teoría mejor demuestra la falsedad de una anterior. A continuación se aborda la noción de sentido común para mostrar que es un elemento útil para el ser humano en la toma de decisiones razonables.

\section{El sentido común}

Antes de continuar, es fundamental no confundir el sentido común al que apela Perelman con el sentido común al que apela Descartes (1999b). Para el autor del Discurso del Método, esta noción remite a una capacidad humana innata, tal como la razón. De tal manera que todos la poseen, aunque no hagan el mismo uso de ella.

El poder de juzgar rectamente, distinguiendo lo verdadero de lo falso, poder llamado por lo general buen sentido, sentido común o razón, es igual por naturaleza en todos los hombres; por eso la diversidad que en nuestras opiniones se observa, no procede de que unos sean más razonables que los otros, porque como acabamos de decir, el buen sentido es igual en todos los hombres; depende de los diversos caminos que sigue la inteligencia y de que no todos consideramos las mismas cosas (Descartes, 1999b:9).

Para Perelman en cambio tiene que ver más con una actitud que busca conformarse con lo aceptado generalmente. Entonces, lo que pueda tomarse por razonable depende del momento o la situación (contexto). Aunque explica que, si bien lo razonable no puede depender únicamente del sentido común, puesto que es un esfuerzo para dar mayor coherencia, claridad y sistematización al punto de vista, sin embargo, los criterios de elección entre sistemas filosóficos opuestos siguen siendo las opiniones generales y la realidad común. Así pues, la dialéctica de lo racional y lo razonable se plantea como base del progreso del pensamiento. Esto, como se verá más adelante, se asemeja al planteamiento de Popper sobre el sentido común.

Una de las características del hombre considerado como persona consiste en ser responsable de su propio destino, es decir, puede tomar sus propias decisiones. Puede adelantarse al futuro y actuar de manera tal que consigue aquello que quiere. Si bien en ocasiones las consecuencias difieren de lo deseado, no es eso lo cotidiano y por ello sigue confiando en los cálculos realizados. Cada ser humano se hace una imagen del mundo que le permite moverse en él y dependiendo de la mayor o menor concordancia de ella con el exterior, sus decisiones son más o menos afortunadas.

Esto sitúa el problema en el debate entre realistas e idealistas. ¿Hay realmente un mundo exterior o aquello que creemos que existe no es más que una creación de nuestra mente? La pregunta es clave para poder aceptar la posibilidad del conocimiento objetivo al que apela la ciencia, o conformarnos con la mera subjetividad de la posmodernidad.

En su Defensa del sentido común (1983), G. E. Moore se refiere a dos párrafos con proposiciones cuya verdad afirma conocer. Además, sostiene que negar dichas proposiciones es una contradicción. Las proposiciones afirman la existencia de cosas y relaciones que se dan en el tiempo y el espacio y que no dependen de hechos mentales o lógicos.

Un ejemplo del tipo de proposiciones de las que habla Moore tiene que ver con la existencia de la tierra:

\begin{abstract}
Una expresión como «la tierra ha existido durante muchos años» es un auténtico caso de expresión sin ambigüedad, cuyo significado todos entendemos. Me da la impresión de que quien adopta un punto de vista contrario confunde el problema de si entendemos su significado (cosa que realmente nos ocurre a todos) con el problema de si sabemos qué quiere decir, en el sentido de ser capaz de hacer un análisis correcto de su significado (Moore,1983:53-54)
\end{abstract}

El problema con el planteamiento de Moore, está en la imposibilidad de refutar las verdades de sentido común que presenta. De tal manera que el diálogo quedaría anulado y la única posibilidad sería el mero cálculo lógico de las consecuencias de esas proposiciones. Una propuesta como esta sería una negación de la retórica que precisamente habla de la posibilidad de una buena opinión, aun si no está basada en verdades irrefutables y evidentes como las de la ciencia.

Al conjunto de creencias tenidas por ciertas y al cual se acude a la hora de tomar decisiones en la vida cotidiana se llama sentido común. Pero al contrario de lo planteado por Moore, no son verdades 
inobjetables, tal vez tenga razón en la veracidad de las proposiciones que presenta, pero seguramente el sentido común no se agota en ellas, ya que varía en el tiempo y en el espacio, pues es el resultado de la búsqueda de conocimiento constante del hombre.

Visto así, estamos ante un tema fundamental de la retórica. Al respecto el diccionario filosófico de Ferrater Mora (2002) nos dice:

La retórica es definida por el Estagirita como la contraparte de la dialéctica. Ni una ni otra son ciencias especiales, sino que se refieren a asuntos conocidos de todos los hombres. Todos usan, pues, naturalmente de la retórica, aunque poco la utilicen como arte. Retórica y dialéctica están, así, estrechamente relacionadas con el saber. Ambas se fundan en verdades (aunque en verdades de opinión comunes) (Ferrater Mora,2002:3084)

Así pues, la retórica apela al sentido común, pero no como lo planteara Moore, porque no se trata del mero cálculo lógico, sino de las verdades que se aceptan comúnmente.

Más cercano a esta idea del sentido común en la retórica está Karl R. Popper cuando plantea en Conocimiento objetivo, un enfoque evolucionista (2001):

La ciencia, la filosofía, el pensamiento racional deben surgir todos del sentido común. Sin embargo, el sentido común no es un punto de partida seguro: el término "sentido común" que aquí empleo es muy vago, porque denota algo vago y cambiante -los instintos y opiniones de la gente, muchas veces adecuados y verdaderos, pero muchas otras inadecuados o falsos (Popper,2001:42)

¿Pero cómo podría el sentido común, en tanto conocimiento del mundo, brindarnos seguridad si puede cambiar? La respuesta es posible siempre que no se intente hacer una filosofía fundacionista. Es decir, una filosofía que quiera partir de bases sólidas e irrefutables, al estilo de Descartes. Si algo hemos aprendido es que el conocimiento está siempre creciendo y que todo sistema sólido ha encontrado algún otro sistema que lo desvirtúa.

Popper propone que el sentido común es el punto del que surgen la ciencia, la filosofía y el pensamiento racional, en tanto que se presenta como posibilidad de crítica de sí mismo. Es decir que el crecimiento del conocimiento sistemático se da precisamente al criticar el conocimiento del sentido común y al hacerlo lo modifica.

Popper considera que el sentido común es el credo fundamental del realismo oponiéndose a la opinión de filósofos como Descartes. Aunque no niega la verdad del punto de partida cartesiano, es decir la aceptación de la existencia a partir de la duda, no acepta que este funcione como fundamento adecuado para el conocimiento. En general no considera que las experiencias subjetivas de tipo observacional sean fundamento estable para el conocimiento. Con lo cual niega la posición idealista.

Frente al realismo y al idealismo Popper considera que son indemostrables e irrefutables, pero que existen buenas razones para aceptar el primero y descartar al segundo. Para esto presenta cinco argumentos que pueden resumirse así: 1) Es una combinación de dos argumentos a) Que el realismo es parte del sentido común. b) Que la mayoría de los argumentos en contra están basados en la teoría errónea de "la mente como un cubo". 2) Que el realismo científico implica que si las teorías científicas son verdaderas implican la verdad del realismo, en tanto que la ciencia es una pretensión de descripción o explicación de la realidad. 3) La característica esencialmente descriptiva del lenguaje. 4) Que el idealismo conduce a una actitud megalómana al negar el realismo creyendo que la mente de uno crea el mundo y 5) Que si el realismo es verdadero las razones por las que no se puede probar son: que el conocimiento es una adaptación tentativa a la realidad, que no existe garantía de no errar y que no tendría sentido el problema de la verdad si no hay realidad.

Podemos afirmar pues, que el sentido común no es un conjunto de proposiciones inobjetables y universalmente aceptadas sobre la existencia del mundo real, a partir del cual se debe construir el conocimiento. Sin embargo, tampoco es cualquier conjunto de creencias caprichosas y subjetivas de cualquier individuo. El sentido común es una construcción colectiva que parte del ejercicio de la razón. Particularmente del ejercicio razonable de la razón. Son creencias ordenadas de manera coherente entre sí, de forma tal que si una es puesta en duda o 
entra en contradicción con las otras genera una crisis en el sistema que implica su revisión.

\section{Una reflexión sobre lo racional y lo razonable en el ámbito del derecho}

Toda esta reflexión sobre la teoría de la argumentación y su inscripción en el ámbito de lo razonable más que de lo racional genera reflexiones sobre la manera en que se discute cotidianamente. El sentido común permite que un individuo o colectivo humano acepte o deseche las tesis de alguien más. De tal manera que los conflictos humanos que no quieran solucionarse violentamente requieren de un manejo adecuado de los conceptos expuestos. Entendemos que una de las herramientas más valiosas para gestionar conflictos humanos es el derecho, de tal manera que el estudio de la nueva retórica podría ayudar a mejorar la práctica jurídica y, de esa manera, la convivencia ciudadana.

Es bien sabido que el ejercicio del derecho, particularmente el colombiano, ha sido influenciado fuertemente por el positivismo, al igual que las demás ciencias sociales. Dicha influencia ha llevado a adoptar formas pretendidamente racionales para inferir las conclusiones propias de cada disciplina. De allí la idea de silogismo jurídico en el que se utiliza la lógica (propia de lo racional) para garantizar que el veredicto sea indudable. La premisa mayor es una norma jurídica, la premisa menor es el hecho juzgado y la conclusión la decisión tomada por el juez.

No obstante, como enseñan Irving $M$. Copi y Carl Cohen (2007), formalmente hablando, el silogismo es una estructura lógica en la que a partir de unas proposiciones llamadas premisas se infiere una nueva proposición llamada conclusión. Una proposición es una afirmación o negación sobre el mundo que es susceptible de ser verdadera o falsa. Pero la conclusión a la que se llega en el silogismo jurídico no cumple esta característica, porque no se concluye una descripción sobre el mundo, sino que se dicta una orden. Para seguir en el lenguaje de Copi, no se llega a un uso descriptivo del lenguaje, sino a un uso directivo del mismo. La forma adecuada de valorar una conclusión de este tipo no es como verdadera o falsa sino como justa o injusta.

Además, la certeza de una decisión jurídica no es total y libre de duda, pues aun aplicando el silogismo, el juez tiene que hacer una valoración del hecho puntual y una interpretación que relacione ese caso con la norma general. Así mismo, la elección de la norma con que se juzga el caso está al arbitrio del juez. En este sentido debe hacerse una valoración de carácter razonable para su elección.

En un caso al que asistimos una joven fue detenida al ser sorprendida robando algunos utensilios de un restaurante. El robo es de menor cuantía y la joven no representa un peligro real para la sociedad. Apegándose a la ley, como se hace en innumerables oportunidades generando el repudio social, el juez podía dejar a la acusada en libertad mientras se adelantaba el proceso. No obstante, dado su lamentable estado de salud, su aparente estado de mal nutrición, y la posibilidad de que esta mujer de 19 años pudiera ser agredida por alguna de sus víctimas o por su compañero sentimental, el juez decide que se mantenga detenida mientras se adelanta el caso. Adujo en su decisión que su papel como juez de la república es garantizar los derechos de todos los ciudadanos y eso incluía los derechos de los acusados. Efectivamente hay un caso de razonabilidad, más que de racionalidad en este ejemplo; una atención a las creencias de sentido común: ¿Qué podría pasarle a la acusada si es dejada en libertad? ¿Qué es lo más deseable en este caso para garantizar que no se cometa un nuevo crimen? Son preguntas sobre lo probable, no sobre lo evidente, y aun así, sobre esa probabilidad se pronunció el juez en este caso.

Otra situación en la que la racionalidad del derecho queda en entredicho es la decisión con base en la duda razonable. Precisamente la racionalidad moderna instaurada con Descartes asume la evidencia de la verdad y por lo tanto su valoración es indudable. Una decisión tomada porque no se tienen elementos suficientes para tomar otra diferente, no cumple precisamente con esta pretensión de la racionalidad.

Un ejemplo de ello se encuentra en Sentencia de la Sala Penal del Tribunal Superior de Armenia, Quindío con radicado 63001600003320901243 aprobada con acta 098 del primero de julio de dos mil dieciséis, en la que se hace un análisis a la prueba testimonial brindada por testigos presentados por la fiscalía, cuyas versiones fueron impugnadas por el juez de conocimiento toda vez que los testigos se 
contradijeron sembrando duda en él, tornándose imposible demostrar el rol desempeñado por el acusado en los hechos investigados. Fue necesario que la Judicatura valorara ambas versiones teniendo en cuenta las razones aducidas por los testigos y agotara un proceso de comparación antes que de eliminación para establecer cuál de ellas se ajustaba a la realidad y así poder tomar una decisión. Debió tener en cuenta que los testimonios de las personas pueden verse afectados por sentimientos, conveniencias (sobornos, amenazas, temores) y cambiar su versión de los hechos o negarse a dar testimonio. Después de haber realizado el análisis comparativo, el Tribunal decidió dar valor probatorio a los testimonios, para concluir que a partir de la comparación de los argumentos dados en entrevista y en el juicio, era más viable absolver al acusado ya que estos testimonios crearon dudas sobre la participación del acusado en el homicidio.

En este caso no se determinó racionalmente que el acusado no cometió el crimen que se le imputaba, simplemente que las pruebas recaudadas no eran suficientes para probar esa culpabilidad. El acusado es declarado inocente, no porque se haya probado que lo es, sino porque no se pudo probar lo contrario.

Este no es, ni más faltaba, un ataque al derecho y su utilidad. Todo lo contrario, lo que se quiere establecer es la importancia de la razonabilidad en esta instancia fundamental de la vida comunitaria, en la que, si bien no se aplican los criterios positivistas de racionalidad, no por eso queda al capricho de los jueces, sino que las decisiones deben estar ajustadas a la razón.

\section{Conclusión}

A pesar del descrédito sufrido por la retórica, particularmente desde la modernidad, se ha presentado aquí la importancia que tiene para la vida en común. Lejos de ser la argumentación un conjunto de técnicas para engañar o seducir al auditorio, se presenta como el estudio de técnicas para acrecentar la adhesión del auditorio a las tesis del orador. Si bien es cierto que puede haber una persuasión irracional que apele a los sentimientos, la teoría de la argumentación quiere comprender el uso legítimo de la persuasión, que apela a la razón.
Con ese objetivo en mente, se ha establecido en este artículo que el sentido común, en tanto conjunto de creencias tenidas por ciertas que permite tomar decisiones en la vida cotidiana, no es algo que se pueda considerar irracional. Por el contrario, la exigencia de coherencia entre las diferentes creencias del sentido común lo inscribe dentro del ámbito de lo razonable.

Por otro lado, está clara la diferencia entre lo razonable y lo racional en tanto usos de la razón. Este último como una apelación a la evidencia irrefutable, propio del discurso científico, poco efectivo en el mundo de las relaciones sociales. El primero como posibilidad de acuerdo, aun en aquellos puntos discutibles, precisamente posibilitador del diálogo y la construcción de vida en común.

Así mismo, tenemos la teoría de la argumentación como disciplina que estudia las técnicas de persuasión del auditorio. Es decir, de qué manera se logra que otra persona o grupo de personas acepten las tesis presentadas por un orador. Pero al argumentar, para que la persuasión sea legítima, se debe apelar a la razón, no a los sentimientos. Quedó claro también que la argumentación aparece en Grecia para formar a los ciudadanos en la participación en la vida pública, para poder tomar parte en las discusiones políticas. De tal manera que no estaba pensada la retórica para demostrar teorías científicas, sino más bien para influir sobre las decisiones de la vida cotidiana.

Este uso razonable de la razón de la teoría de la argumentación mostró su utilidad en las discusiones de la vida en común, particularmente en el derecho. Este último aparece como la manera en que la modernidad pretendió solucionar los conflictos entre los ciudadanos. El asunto es que muchos asumieron para lo jurídico una condición racional y han pretendido que su ejercicio, en tanto sustentado en el silogismo, es evidente y verdadero; al punto de equiparar la aplicación del derecho con la justicia. Pero precisamente se ha visto que no es así, que las sentencias judiciales dejan algún resquicio para la discusión, razón por la cual se contempla la figura de la doble instancia, para revisar una decisión que no parece razonable. 
Queda claro pues, que en el intento de persuadir al otro debe apelarse al conjunto de creencias que se tienen por ciertas y que permiten tomar decisiones en la vida cotidiana. Es decir la argumentación no apela primordialmente a los conocimientos lógicos, matemáticos o científicos del auditorio, sino que apela al sentido común; no se inscribe dentro del ámbito de lo racional, sino de lo razonable.

\section{Bibliografía}

Arango, P R. (2005). Introducción a la filosofía moral. Manizales: Universidad de Caldas.

Aristóteles. (1994). Retórica. Madrid: Gredos.

Ayer, A. (1984). Lenguaje, verdad y lógica. Barcelona: Orbis.

Copi, I M. \& Cohen, C. (2007). Introducción a la lógica. México: Limusa.

Descartes, R. (1999a). Discurso del método. México: Porrúa.

Descartes, R. (1999b). Meditaciones metafisicas. México: Porrúa.

Dussel, E. (1982). Ética de la liberación. Iglesia viva 102, 591-599.

Ferrater, J. (2002). Diccionario de filosofía. Barcelona: Ariel.

Gómez, A L. (2001). Seis lecciones sobre teoría de la argumentación. Cali: Alego.

Jaeger, W (2001) Paideia: los ideales de la cultura griega. México: Fondo de Cultura Económica.

Kant, I. (1991) Crítica del Juicio. México D.F: Porrúa.

Kant, I. (1996) Fundamentación de la metafísica de las costumbres. Barcelona: Ariel

Moore, G E. (1983). Defensa del sentido común y otros ensayos. Barcelona: Orbis.

Perelman, Ch. (1979) The Rational and the
Reasonable. Philosophic Exchange 10 (1), 29-34. En: http://digitalcommons. brockport.edu/phil_ex/vol10/iss1/5

Perelman, Ch. \& Olbrechts-Tyteca, L. (1989) Tratado de la argumentación, la nueva retórica. Madrid: Gredos.

Popper, K R. (2001) Conocimiento objetivo, un enfoque evolucionista. Madrid: Tecnos.

Posada, J G. (2011). El razonamiento silogístico como patrón básico del pensamiento moral y cientifico. Sophia 7, 48-57.

Tribunal superior del distrito judicial de armenia, Sala penal de decisión (julio 1 de 2016). Confirmar la sentencia proferida por el juzgado Quinto Penal del Circuito de Armenia.

Urrea, J (2010) Lógica del sinsentido en la obra de Lewis Carroll. Medellín: La Carreta.

Von Wright, G H. (1970) Norma y acción, una investigación lógica. Madrid: Tecnos. 